\title{
IMPACTO DO PRONAF NO CRESCIMENTO ECONÔMICO DOS MUNICÍPIOS PARANAENSES NO PERÍODO DE 2012 A 2016
}

\author{
PRONAF'S IMPACT ON THE ECONOMIC GROWTH OF \\ MUNICIPALITIES IN THE PARANA STATE FROM 2012 TO 2016
}

\section{Wanderson Dutra Gresele}

Mestre em Administração pela Universidade Federal do Paraná (Curitiba/Brasil).

Professor na Universidade Estadual do Oeste do Paraná (Marechal Cândido Rondon/Brasil).

E-mail:wanderson.gresele@hotmail.com

\section{Jackson Rodrigo Brun}

Graduado em Administração pela Universidade Estadual do Oeste do Paraná (Marechal Cândido Rondon/Brasil).

E-mail: jacksonbrun21@gmail.com

\section{Silvana Anita Walter}

Doutora em Administração pela Pontifícia Universidade Católica do Paraná (Curitiba/Brasil).

Professora na Universidade Estadual do Oeste do Paraná (Marechal Cândido Rondon/Brasil).

E-mail: silvanaanita.walter@gmail.com 


\section{RESUMO}

O presente estudo analisou o impacto dos recursos do Programa Nacional de Fortalecimento da Agricultura Familiar (Pronaf) no crescimento econômico dos municípios do Estado do Paraná. No processo de coleta foram extraídos dados referentes aos recursos de custeio e investimento, tanto agrícola quanto pecuário, fornecidos no sítio do Banco Central do Brasil (BACEN), e indicadores econômicos, como o Produto Interno Bruto (PIB) per capita municipal; Valor Adicionado Bruto (VAB) setoriais do Agronegócio, Comércio e Serviços e Indústria, disponibilizado pelo Ipardes, de 385 municípios paranaenses do período de 2012 a 2016. Para análise foram utilizados os softwares SPSS, para executar estatísticas descritivas e análise de grupamentos (clusters), Stata, para a análise de regressão linear com dados em painel, e Qgis, para apresentação espacial do agrupamento dos municípios. Nos resultados, chegou-se à conclusão de que o programa Pronaf teve efeito significativo e positivo sobre o Produto Interno Bruto (PIB) per capita municipal em três dos quatro agrupamentos encontrados na clusterização e para o estado do Paraná. Ainda, parece indicar que o grau desse efeito está relacionado à interação das características econômicas com o volume de recursos.

Palavras-chave: Políticas Públicas. Pronaf. Produto Interno Bruto. Agricultura Familiar. Crescimento Econômico.

\section{ABSTRACT}

This study analyzed the impact of the National Program to Strenghten Family Farming (Pronaf) resources on the economic growth of the Paraná State's counties. The extracted data referred to costing and investment resources, both agricultural and livestock, provided on the website of the Central Bank of Brazil (BACEN), and economic indicators, such as the municipal Gross Domestic Product (GDP) per capita; Gross Value Added (VAB) sector of Agribusiness, Commerce and Services and Industry sector. These informations were available by Ipardes, from 385 Paraná municipalities from 2012 to 2016. For data analysis, SPSS software was used to perform descriptive statistics and analysis of clusters, Stata was used for linear regression analysis in panel data, and Qgis was used for spatial presentation of the cluster's counties. It was concluded that the Pronaf program had a significant and positive effect on the per capita gross domestic product in 3 of the 4 clusters found in the cluster analysis and in the state of Paraná. It seems to indicate that the degree of this effect is directly related to the interaction of economic characteristics with volume of resources.

Keywords: Public Policy. Pronaf. Gross Domestic Product. Family Farming. Economic Growth.. 


\section{INTRODUÇÃO}

O atual cenário mundial retrata esforços cada vez maiores dos países para a produção. As iniciativas são concentradas na alteração dos impostos, gastos do governo, taxas de juros, mudanças políticas, investimentos em infraestrutura, tanto no setor público quanto privado, e investimentos no setor agropecuário, visando elevar o desenvolvimento econômico e melhorar a qualidade de vida da sua população.

Nos últimos anos, grande parte das economias mundiais apresentou redução na taxa de crescimento do Produto Interno Bruto, PIB. Segundo dados do Fundo Monetário Internacional (FMI), divulgados pelo Instituto de Pesquisas Econômicas Aplicadas (IPEA, 2018), a recuperação do crescimento mundial deve ocorrer com expansão bem menor do comércio internacional, quando comparada com a década de 2000 : em média, 4,2\% ao ano, enquanto em 2018 foi de 3,6\%, 2019 de 1,1\%, ante 6,7\% ao ano de 2000 a 2008.

O Brasil também apresentou uma retração em sua economia nos últimos anos. Em meio a tempos de crise econômica e política, o último índice de crescimento expressivo do país foi em 2010, quando o PIB teve crescimento de 7,5\%, chegando a R\$ 4,554 trilhões. Desde então houve uma desaceleração da economia brasileira, com variação da economia, medida pelo PIB, em -3,8\%; -3,5\%; 1,3\%; 1,1\% e 1,1\%, respectivamente nos anos de 2015 a 2019, conforme dados divulgados pelo Instituto Brasileiro de Geografia e Estatística (IBGE, 2019).

Em períodos de crise, ações do Governo são estratégicas para tentar conter os impactos causados pela retração da economia. No âmbito nacional, o Governo é fomentador de grande parte dos investimentos realizados no setor agropecuário. Políticas públicas são empregadas com o intuito de sanar as necessidades da população, promovendo melhorias não só econômicas, mas também elevando padrões de qualidade de vida, tais como educação, saúde e bem-estar social (SANTOS et al., 2012; HANAUER; TEIXEIRA, 2015). Nessa lógica, o Programa Nacional de Fortalecimento da Agricultura Familiar (Pronaf) se destaca como uma ferramenta de incentivo à produção agrícola familiar, disseminando recursos financeiros a esse público, de modo a impactar, positivamente, sua realidade socioeconômica.

No Brasil, o modelo de desenvolvimento rural está passando por mudanças estruturais, com vistas a superar as dificuldades produtivas, preservar os recursos naturais e aumentar a renda, o que se torna um grande desafio. Neste contexto, políticas públicas voltadas à agricultura têm sido fundamentais para alcançar esses objetivos. É nessas circunstâncias que surge, em 1995, o Programa Nacional de Fortalecimento da Agricultura Familiar (Pronaf) (MDA, 2017).

O Pronaf trata de uma política pública de crédito subsidiado à agricultura familiar, que custeia a produção e promove investimentos na propriedade rural, contribuindo com o crescimento da renda de 
seus beneficiários. Um dos objetivos do programa é promover a inclusão social, por meio da inserção tecnológica com baixo custo. Desta forma evidencia-se a importância do Pronaf na promoção do desenvolvimento rural e todo o seu impacto no sistema econômico, bem como no ambiente municipal (GEHLEN, 2004).

Deve-se reconhecer que o Pronaf colabora não só para a superação das dificuldades econômicas e sociais dos produtores familiares como também para alçar este segmento a uma posição estratégica, a fim de dinamizá-lo para alcançar o desenvolvimento local (Ortega, 2008). Para a economia de uma região, o setor rural é uma peça fundamental que contribui fortemente para o desenvolvimento e implementação de políticas públicas.

Diante deste cenário, tal como indica Santos (2001), nos pequenos e médios municípios brasileiros, a agricultura é o principal agente do desenvolvimento da economia, em que os incentivos no setor atuam como um efeito multiplicador de renda, fomentando os demais setores da economia. De outro modo, o desenvolvimento e a distribuição de renda do setor rural condicionam e mantêm a qualidade de vida nos municípios.

Segundo o Ministério do Desenvolvimento Agrário (MDA, 2019), dos 5.570 municípios da federação brasileira, entre os anos de 1999 e 2000, o Pronaf já conseguia abranger 3.403. Em 2003 e 2004, ocorreu a contratação de $\mathrm{R} \$$ 4,49 bilhões por agricultores familiares e, nos anos de 2007 e 2008, o programa foi capaz de assistir a 5.379 municípios brasileiros, alcançando, assim, 96,57\% do total. No geral, o Pronaf abrange praticamente todo território nacional, estabelecendo-se como um dos principais agentes fomentadores de apoio à agricultura do pequeno produtor rural no país, bem com responsável por injetar expressivos numerários na economia de vários municípios, com maior expressão nas regiões de menor orçamento, como indica Santos (2001).

Diante disto, forma-se o seguinte questionamento: Qual o impacto dos recursos do Pronaf no

crescimento econômico dos municípios do estado do Paraná? Como objetivo geral, busca-se analisar o impacto dos recursos distribuídos pelo Pronaf e o crescimento econômico dos municípios do estado do Paraná. Assim, se verificará os recursos do Pronaf aportados em cada município do estado do Paraná; apresentará o PIB per capita e sua representatividade nos municípios do Paraná; relacionará os recursos do Pronaf com o PIB dos municípios do estado do Paraná conforme suas características econômicas; e verificará o impacto do Pronaf no PIB per capita durante o período de 2012 a 2016.

A partir desta problematização, torna-se, assim, relevante fazer uma análise do potencial dos recursos distribuídos pelo Pronaf, enquanto relação com o crescimento econômico nos municípios, com caráter de produção familiar e produtivo do estado do Paraná, e investigar a quantidade de recursos destinados dentro de suas modalidades comparados com o PIB per capita. Ademais, este estudo busca 
demonstrar a importância de se analisar de políticas públicas federais nos contextos municipais, podendo comparar impactos diferenciados do Pronaf nos municípios, neste caso, os paranaenses.

\section{FUNDAMENTAÇÃO TEÓRICA}

\subsection{DESENVOLVIMENTO RURAL E CRESCIMENTO ECONÔMICO}

A discussão sobre o desenvolvimento econômico se divide em duas vertentes: a primeira propõe que crescimento econômico é o mesmo que desenvolvimento, em que o conjunto de crescimento populacional, nível de emprego e arrecadação pública permitem ao Estado intervir promovendo melhorias sociais; e a segunda indica que o crescimento econômico, por si só, não é suficiente para gerar o desenvolvimento (SOUZA, 2007).

Desenvolvimento econômico, na opinião de Bresser-Pereira (1962), está atrelado ao aumento da renda per capita por meio de um rearranjo dos meios de produção. Essa análise não o distingue completamente de crescimento econômico, porém ambos requerem o aumento de produtividade de bens e serviços. A distinção acontece devido à promoção do desenvolvimento econômico só ocorrer a partir de transformações econômicas e sociais, e o crescimento econômico apenas requerer o aumento da renda. Esses processos de mudanças da produção e do capital humano ocorrem em estágios, evoluindo a economia em questão.

Uma análise de desenvolvimento que pode ser aplicada tanto em escala nacional quanto regional, apontando que o desenvolvimento acontece por meio de um estímulo endógeno ou exógeno à produção, sendo isto o incentivo ao investimento e à poupança, reestruturando a agricultura, fomentando a indústria e modificando a forma de explorar e transformar a produção local. O desenvolvimento aconteceria em uma sociedade primária que recebesse estímulos à sua produção, fomentando sua cadeia de produção. Assim, deixaria de ser apenas agrária e evoluiria para produção industrial, o comércio e a prestação de serviços, ao mesmo tempo em que seus métodos produtivos e relações sociais também se modificariam (ROSTOW, 1978).

Em linhas gerais, o desenvolvimento é um complexo processo de transformações nas esferas econômicas, políticas, humanas e sociais de uma sociedade. Mais do que o crescimento produtivo, é uma construção de melhorias dos serviços provedores do bem-estar humano, isto é, a saúde, a educação, a habitação, o transporte e a alimentação. A partir das informações conceituadas, conclui-se que o desenvolvimento engloba mais que o crescimento econômico por si só. A elevação de uma renda média 
não implica, necessariamente, em melhorias sociais, tais como o enriquecimento de capital humano, avanços na saúde e saneamento (OLIVEIRA, 2002).

Ainda, deve-se considerar que expansão da renda é um fator presente. Só é possível superar a desigualdade social, de acordo com Hoffmann (2001), por meio do crescimento econômico. As origens das divergências econômicas são diversas e têm sua gênese de acordo com a formação e evolução econômicosocial. Nesse sentido, a distribuição de renda surge como mecanismo de redução dessa desigualdade e como ferramenta capaz de minimizar a pobreza.

Assim, desenvolvimento rural é um acontecimento premeditado, induzido, principalmente, por parte do Estado, tornando-se este o agente principal de transformação, agindo por meio de estratégias, projetos e ações que priorizam o setor agrário. O desenvolvimento agrícola se relaciona estritamente às condições de produção agropecuária, fazendo referência às características produtivas, como área de plantio, tecnologia empregada à produção, produtividade, redução de custos e o trabalho como fator de produção. (NAVARRO, 2011). Em especial a agricultura familiar, em que membros da família estão intrinsecamente ligados na condução da produção. Assim, há uma estreita relação afetiva e cultural no meio rural, existindo, assim, um forte vínculo com o trabalho físico e emprego emotivo com a terra (BAIARDIL; ALENCAR, 2014).

No Brasil, a agricultura familiar é essencial para o desenvolvimento e crescimento equilibrado. Isto porque ela é composta por uma significativa parcela da população rural brasileira, que produz boa parte dos alimentos consumidos no país, participando, assim, da geração de postos de trabalho, do aumento e da distribuição de renda, bem como evitando a migração populacional do meio rural para os centros urbanos (DAMASCENO; KHAN; LIMA, 2011).

Entretanto, durante o crescimento econômico vivido pelo país no período anterior à década de 1980, um número expressivo de pequenos agricultores não participou desse ganho financeiro e ainda teve sua situação econômica agravada. Os créditos financeiros direcionados à agricultura estavam voltados ao financiamento de agroquímicos, sementes certificadas e investimentos em máquinas e equipamentos do setor, destinados aos grandes produtores já integrados ao mercado agrícola. Esse modelo resultou em uma redução significativa das áreas agrícolas cultivadas por pequenos agricultores, agravando a situação (SCHNEIDER, 2010; BIANCHINI, 2015).

Com o fim do regime militar, a promulgação da Constituição de 1988 e a crise do modelo agrícola adotado anteriormente, surgem as organizações de grupos de agricultores. Neste novo ambiente se reestabelece um rearranjo institucional que de um lado era representado pelos grandes proprietários além do forte interesse no capital agrícola e do outro lado pelas instituições que defendiam uma política 
de incentivo ao pequeno produtor e buscava melhoria de direitos na sociedade, por intermédio da reforma agrária e da agricultura sustentável (BIANCHINI, 2015).

Após muitas reivindicações dos movimentos sindicais rurais, no ano de 1994 é criado o Programa de Valorização da Pequena Propriedade Rural (Provap). No ano seguinte, é formado o Programa Nacional de Fortalecimento da Agricultura Familiar (Pronaf), já com definição de taxa de juros, fonte de recursos e voltado, especificamente, ao atendimento do agricultor familiar (MDA, 2015).

A disputa presidencial do ano de 1994 obrigou a proposta de campanha de Fernando Henrique Cardoso a se comprometer com a classe agrícola familiar, pois seu principal oponente, Luiz Inácio Lula da Silva, tinha em sua proposta de governo o total incentivo ao pequeno produtor rural (BIANCHINI, 2015). O Pronaf nasceu como uma resposta para suprir o escasso e oneroso crédito agrícola ofertado, em especial aos produtores familiares. O programa se estabeleceu com a proposta de ofertar uma política de remuneração moderada e de alto valor percentual subsidiado, com condições de pagamento e carências especiais (GUANZIROLI, 2007).

Neste sentido, a Resolução 2.191, de 24 de agosto de 1995, do Banco Central do Brasil, denota que em seu artigo primeiro o Pronaf destina subsídio financeiro, e que, entre outros objetivos a atingir, o emprego da força de trabalho familiar seja um deles. O Pronaf seguia, portanto, a perspectiva de que a agricultura familiar, cada vez mais, deveria ser direcionada rumo à agricultura de mercado. Contudo, com a evolução do programa, seu enfoque foi redirecionado, passando a proporcionar a inclusão de seus beneficiários, visando ao desenvolvimento sustentável e à construção e ao fortalecimento das cadeias produtivas locais (FREITAS; FREITAS; DIAS, 2012; LOPES et al., 2016).

No geral, as modalidades disponibilizadas pelo Pronaf se dividem em quatro grupos: custeio agrícola, custeio pecuário, investimento agrícola e investimento pecuário (BACEN, 1995). Todas as categorias de disponibilidade de recursos visam proporcionar aos seus beneficiários crédito para aquisição, ampliação ou manutenção de fatores necessários para a promoção da agricultura familiar.

Mais importante, como Buainain, Romeiro e Guanziroli (2003) mostram, com apoio, seja por meio de cooperativismo, seja auxílio governamental, o agricultor familiar é capaz de gerar renda suficiente para se manter na atividade rural. A agricultura familiar, quando comparada com a agricultura patronal, tornase mais diversificada e eficiente quando recebe incentivos, mesmo com uma área de produção e recursos financeiros inferiores, gerando mais empregos. Feijó (2001), do mesmo modo, aponta os impactos do Pronaf no crescimento da produtividade, em que sugere que o programa tenha começado a surtir melhores resultados depois da criação do programa. 


\subsection{PESQUISAS QUE RELACIONAM O PRONAF COM DESENVOLVIMENTO ECONÔMICO}

Pesquisas que tratam do crédito rural, tal como apresentam Faria e Santos (2014), não são novidade no Brasil. $\mathrm{O}$ efeito do Pronaf com o desenvolvimento econômico tem sido um tema que tem instigado o interessado de diferentes pesquisadores. Mattei et al. (2007) analisaram os impactos da aplicação de recursos do Pronaf sobre as economias locais, através dos efeitos sobre a dimensão produtiva, demográfica, social e tributária, em oito estados das regiões Nordeste, Sudeste e Norte. Constataram uma relação positiva, ainda que baixas, em todas as dimensões, impactos mais consistentes aparecem na esfera produtiva, especialmente na produção agrícola.

Assunção e Chein (2007) buscaram obter a evolução do Pronaf no Brasil durante os anos 2000 e 2004 e sua relação com variáveis socioeconômicas. Os autores observaram primeiramente que, durante o período analisado, houve uma tendência de desconcentração dos recursos totais do Pronaf entre as regiões brasileiras. No caso dos recursos para custeio, verificou-se um forte indício de correlação positiva entre o total financiado e indicadores associados a um maior nível de desenvolvimento. Entre as variáveis analisadas, encontrou-se uma correlação positiva e fortemente significativa entre o volume financiado de crédito e a renda média per capta, a média de anos de estudo e o número de agências bancárias por mil habitantes. Também se observou uma correlação positiva com a produtividade agrícola e negativa em relação ao índice de Gini de riqueza.

O trabalho de Silva e Pires Filho (2009) objetivou analisar a ação do Pronaf em um âmbito territorial para a região do Médio Jequitinhonha, Minas Gerais, e verificar os impactos econômicos que essa política vem provocando nas economias locais. Nos resultados os autores apresentam que o impacto do crédito do Pronaf em relação ao produto agregado da economia do território afeta positivamente o PIB total e os três setores analisados separadamente, indicando a contribuição para o desenvolvimento das economias locais.

Camara etal.(2010) analisaram o impacto do Pronaf na economia local dos 60 municípios paranaenses que mais contrataram crédito no período de 2000 a 2005. Utilizaram modelos de regressão linear simples para mensurar o efeito do Pronaf sobre cada uma das dimensões sociais, tributária e produtiva do estado. Nos resultados comprova-se relações positivas, estatisticamente significativas, entre o crédito do Pronaf e cada umas das variáveis.

O estudo de Castro, Resende e Pires (2014) objetivou avaliar os impactos regionais do Programa Nacional de Agricultura Familiar (Pronaf) entre 2000 e 2010, utilizando-se o instrumental econométrico de modelos de dados em painel com efeitos fixos. Em destaque, os autores combinaram avaliações de impacto em várias escalas e realizaram, separadamente, avaliações de impacto para cada uma das 
cinco macrorregiões brasileiras. Nos resultados constataram que no Nordeste, Sudeste e Sul foi possível verificar impactos positivos do Pronaf sobre as taxas de crescimento do produto interno bruto per capita e do PIB agropecuário municipal; as regiões Norte e Centro-Oeste caracterizaram-se pela ausência de impactos do Pronaf. Ainda, a magnitude dos impactos do Pronaf foi maior nas regiões Sul e Sudeste, demonstrando a importância de desenvolver uma análise regionalizada.

Bueno e Oliveira (2015) analisaram o impacto socioeconômico nos 30 municípios que mais contrataram crédito do Pronaf no estado do Paraná entre os anos 2000 e 2006. Por meio do método de regressão linear simples e correlações entre as variáveis selecionadas nas dimensões produtiva, social e tributária, verificaram um impacto positivo em todas as dimensões, mas na dimensão produtiva verificouse que o Programa teve impacto maior.

Marioni et al. (2016) avaliaram o impacto do Pronaf no PIB da economia brasileira e nos PIB de serviços, agropecuário e industrial por meio de regressão quantílica com efeitos fixos para dados em painel. Nos resultados os autores indicam a presença de impacto positivo do programa sobre o PIB total e PIBs setoriais, mas com diferentes tamanhos de efeitos entre as regiões.

Araújo e Vieira Filho (2018) analisam os impactos do Programa Nacional de Fortalecimento da Agricultura Familiar (Pronaf) na agricultura e pecuária para as 26 Unidades da Federação (UFs) e o Distrito Federal do Brasil no período de 2007 a 2016. Para tal os autores utilizaram-se de vetores autorregressivos em painel para mensurar o efeito dos choques de crédito ofertado pelo Pronaf, através da quantidade e do valor agregado dos contratos da agricultura e pecuária, sobre a área plantada, o valor bruto da produção agrícola e a pecuária e produtividade da terra. Resultados apresentado pelos autores indicam que o impulso-resposta da área plantada, do valor da produção e da produtividade da terra, a um choque no valor do crédito, gerou um retorno positivo durante um período, até mudar de direção e convergir a zero depois do sexto período. Logo, conclui-se que o programa impõe viés de seleção e não estimula o agricultor a diversificar sua produção, o que compromete a promoção do desenvolvimento e a redução da pobreza rural.

\section{MÉTODO}

Com o objetivo de analisar o impacto dos recursos do Pronaf no crescimento econômico dos municípios do Paraná, a pesquisa teve como escopo todos os municípios paranaenses (399). Entretanto devido à falta de informações de alguns municípios, este número se reduziu a 385, que são os que possuíam informações suficientes para a análise. Assim, 14 (quatorze) municípios foram excluídos da análise, sendo Curitiba; Guaraqueçaba; Jardim Olinda; Matinhos; Nossa Senhora das Graças; Paranapoema; Pinhais; 
Pontal do Paraná; Porecatu; Porto Amazonas; Quatro Barras; Santa Inês; Telêmaco Borba; Tunas do Paraná.

Quanto à perspectiva temporal, devido à falta de informações completas disponíveis fornecidas pelo banco de dados do Banco Central do Brasil (BCB, 2019), plataforma da qual foram extraídas informações referentes ao Pronaf, dados até o ano de 2011 não foram utilizados. Ressalta-se também que na plataforma do Instituto Paranaense de Desenvolvimento Econômico e Social, (IPARDES, 2019) encontrou-se os dados referentes ao PIB per capita dos municípios paranaenses até o ano de 2016. Portanto, em relação aos dados, os anos possíveis para esta análise foram de 2012 a 2016.

As variáveis utilizadas foram os recursos aplicados do Pronaf, referentes ao montante de recursos no âmbito municipal fornecidos no sítio do Banco Central do Brasil (BACEN), abrangendo o custeio agrícola, custeio pecuário, investimento agrícola e investimento agropecuário. Também foram utilizados os seguintes indicadores econômicos: o PIB per capita municipal; Valor Adicionado Bruto (VAB) setoriais do Agronegócio, Comércio e Serviços e Indústria, que agrega os bens e serviços consumidos no seu processo produtivo, disponibilizado por meio do site do Ipardes. Considerando que a informação disponível do Pronaf por município iniciou-se no ano de 2012, os dados sobre o PIB per capita também foram coletados a partir deste ano.

Dada a importância de desenvolver uma análise segmentada, como sugere Castro, Resende e Pires (2014), desenvolveu-se uma análise de agrupamentos, ou como é conhecido, análise de clusters, método empírico para realizar a classificação de objetos, neste caso, com o objetivo de simplificação e exploração dos dados (HAIR et al., 2009). Este processo teve o objetivo de separar os municípios conforme características econômicas, utilizou-se para tal a participação da composição dos PIBs da agroindústria, comércio e serviços e agropecuária sobre a composição agregada bruta total nos municípios.

A análise de agrupamentos não é uma técnica de inferência estatística através da qual os parâmetros de uma amostra são avaliados como possivelmente representativos de uma população, mas sim busca quantificar características estruturais de um conjunto de observações. Como ela tem propriedades matemáticas e não estatísticas, não se torna importante as exigências de normalidade, homocedasticidade e linearidade. Entretanto, deve-se se preocupar com a representatividade da amostra e a multicolinearidade (HAIR et al., 2009). Assim, quanto à amostra, é evidente que a presente pesquisa é representativa, pois possui dados de 385 municípios de uma população de 399 no Paraná. Com isso, é possivel afirmar que as observações atípicas pertencem realmente à população em estudo. Já quanto à multicolinearidade, que é a representação dos altos niveis de correlação entre as variáveis independentes, na análise de agrupamentos, as variáveis com essa característica são implicitamente ponderadas com maior peso. 
Foi desenvolvido testes para a análise da multicolinearidade, sugerida por Field (2009), pelos quais os valores de FIV estão todos abaixo de 10 e as tolerâncias todas acima de 0,20, comprovando que os dados não apresentam significativos níveis de multicolinearidade.

O delineamento da análise de agrupamentos seguiu os procedimentos indicados por Hair et al. (2009). Inicialmente, foi analisada a presença de dados atípicos entre aqueles coletados e não se encontrou um forte caso necessário a ser eliminado da base de dados. Além disso, dado que o conjunto de dados trabalhados é considerado métrico, a distância euclidiana quadrática foi utilizada como medida de semelhança e o procedimento hierárquico, por meio do método Ward, foi escolhido para minimizar as diferenças internas de grupos e evitar problemas de encadeamento das ligações. Além disso, desenvolveuse uma padronização das variáveis por meio do score $Z$, haja vista as diferenças de medidas entre as variáveis estudadas.

Assim, buscou-se identificar a existência ou não de parâmetros significativos que indicassem os impactos do volume total de créditos do Pronaf nos municípios do estado do Paraná no PIB per capta municipal. Para tal, utilizou-se de dados em painel por ter a capacidade de lidar com o problema de variável omitida, ou seja, o emprego de modelos com dados em painel é possivel controlar as variáveis omitidas fixas ao longo do tempo (SILVA; PIRES FILHO, 2009; CASTRO; RESENDE; PIRES, 2014).

Para análise, foram considerados três modelos de regressão: POLS (pooled ordinary least squares), Efeitos Fixos e Efeitos Aleatórios. Todos com a variação ao longo do tempo, conhecida por within variance. Como indica Fávero (2013), o passo inicial para a aplicação de um modelo com dados em painel é a aplicação de um modelo POLS, que assume que os regressores sejam exógenos e que o termo de erro seja, conforme apresenta a Equação 01.

$$
y_{i t}=\beta_{0}+x^{\prime}{ }_{i t} \beta_{1}+\mu_{i t}(01)
$$

Os parâmetros desse modelo são estimados por meio de OLS (ordinary least squares), mas a inferência requer que haja controle da correlação within do erro para um dado indivíduo.

Nos Efeitos Fixos, como apresenta Fávero (2013), os regressores devem ser correlacionados com os efeitos do nível do indivíduo e, portanto, uma estimação consistente dos parâmetros do modelo requer uma eliminação ou controle dos efeitos fixos. Assim, é um modelo que leva em conta os efeitos específicos do indivíduo para uma variável dependente especifica, conforme pode ser visualizado na Equação 02.

$$
y_{i t}=\beta_{0 i}+x_{i t}^{\prime} \beta_{1}+\varepsilon_{i t}(02)
$$

Em que são regressores, são os efeitos aleatórios específicos de indivíduo e representa o erro idiossincrático. A vantagem do modelo de Efeitos Fixos é que pode ser obtido um estimador consistente do efeito marginal do j-ésimo regressor de, dado que varia no tempo. 
Efeitos Aleatórios, apresentado na Equação 03, assume-se que é puramente aleatório, ou seja, não é correlacionado com os regressores. Assim, a estimação é elaborada com um estimador FGLS (feasible generalized least squares) (FÁVERO, 2013).

$$
y_{i t}=x_{i t}^{\prime} \beta_{1}+\left(\beta_{0 i}+\varepsilon_{i t}\right) \text { (03) }
$$

Os parâmetros e os termos de erro idiossincrático são independentes e identicamente distribuídos. A vantagem do modelo de Efeitos Aleatórios é que a estimação de todos os coeficientes, mesmo dos regressores invariantes no tempo, e, portanto, os efeitos marginais. O grande problema deste modelo é que os estimadores são inconsistentes se o modelo de Efeitos Fixos for mais apropriado (FÁVERO, 2013).

Assim, para verificar qual dos três modelos, POLS, Efeitos Fixos ou Efeitos Aleatórios, é o modelo mais adequado, foi desenvolvido, seguindo as orientações de Fávero (2013) e Wooldridge (2010), os testes LM de Breusch-Pagan, o teste F de Chow e o Teste de Hausman.

Para análise dos dados encontrados na pesquisa utilizou-se de três softwares: SPSS, Qgis e Stata. O software denominado Statistical Package for the Social Sciences - SPSS, versão 22, foi utilizado com o objetivo de analisar as estatísticas descritivas e os agrupamentos dos municípios. Já o Qgis, que é um software livre e open source, foi utilizado com o objetivo de se ter uma melhor representação dos grupos formados, utilizando-se das coordenadas vetoriais disponíveis pelo Instituto Brasileiro de Geografia (IBGE, 2018) para o estado do Paraná, assim foram desenvolvidos mapas georreferenciados dos grupos dos munícipios analisados. O software Stata, usado geralmente para análises econométricas, foi utilizado com o objetivo de analisar o impacto do Pronaf no PIB per capita por meio da análise de regressão com dados em painel.

\section{APRESENTAÇÃO E DISCUSSÃO DOS RESULTADOS}

\subsection{ESTATÍSTICA DESCRITIVA DAS VARIÁVEIS}

A Tabela 1 apresenta uma síntese da estatística descritiva da variável Pronaf utilizada neste estudo. As informações são referentes aos dados somados de Custeios Pecuários e Agrícolas, Investimentos Pecuários e Agrícolas. 
Tabela 1 - Estatística descritiva da Variável Pronaf

\begin{tabular}{lccccc}
\hline Estatística descritiva & $\mathbf{2 0 1 2}$ & $\mathbf{2 0 1 3}$ & $\mathbf{2 0 1 4}$ & $\mathbf{2 0 1 5}$ & $\mathbf{2 0 1 6}$ \\
\hline Média & $6.198 .848,95$ & $7.646 .741,13$ & $9.353 .237,18$ & $9.329 .910,22$ & $9.992 .837,50$ \\
Mediana & $3.828 .703,64$ & $4.585 .347,07$ & $5.319 .585,48$ & $5.093 .119,76$ & $5.101 .827,07$ \\
Desvio Padrão & $7.020 .120,10$ & $8.938 .565,14$ & $11.753 .970,74$ & $12.061 .198,83$ & $12.635 .154,02$ \\
Coef. de variação & $113,2 \%$ & $116,9 \%$ & $125,7 \%$ & $129,3 \%$ & $126,4 \%$ \\
Menor & $100.054,52$ & $158.533,32$ & $105.885,76$ & $84.369,77$ & $46.088,00$ \\
Maior & $53.478 .828,97$ & $55.333 .700,95$ & $95.509 .074,14$ & $89.894 .754,29$ & $99.492 .903,45$ \\
$1^{\circ}$ quartil & $1.879 .380,49$ & $2.028 .860,30$ & $2.458 .847,88$ & $2.180 .023,44$ & $2.388 .931,63$ \\
$3^{\circ}$ quartil & $8.167 .361,50$ & $10.199 .058,98$ & $12.144 .844,55$ & $11.718 .392,83$ & $12.681 .665,87$ \\
\hline
\end{tabular}

\section{Fonte: os autores (2019)}

Analisando a estatística descritiva das variáveis em estudo, pode-se perceber que o maior valor médio de distribuição de recursos do Pronaf dos municípios paranaenses foi no ano de 2016, R\$ 9.992.837,50 com representatividade de $24 \%$ de participação na média dos períodos, $61 \%$ maior que 0 ano de 2012, que foi o primeiro ano de estudo e que apresentou a menor média dos períodos analisados, apenas $15 \%$ de participação.

Observa-se também na Tabela 1, que analisando os valores médios todos eles apresentam um desvio padrão acima de 100\%, evidenciando uma distribuição dispersa em torno da média, demonstrando pouca homogeneidade em relação aos valores médios.

A Tabela 2 apresenta uma síntese da estatística descritiva da variável PIB per Capita Municipal.

Tabela 2 -Estatística descritiva da Variável PIB Per Capita

\begin{tabular}{lccccc}
\hline Estatística descritiva & $\mathbf{2 0 1 2}$ & $\mathbf{2 0 1 3}$ & $\mathbf{2 0 1 4}$ & $\mathbf{2 0 1 5}$ & $\mathbf{2 0 1 6}$ \\
\hline Média & $24.311,66$ & $31.801,39$ & $42.585,14$ & $52.491,97$ & $62.420,27$ \\
Mediana & $21.363,00$ & $4.679 .580,25$ & $5.506 .708,55$ & $5.135 .372,56$ & $5.256 .710,64$ \\
Desvio Padrão & $13.465,79$ & $8.973 .510,36$ & $11.812 .857,86$ & $12.121 .587,57$ & $12.695 .254,05$ \\
Coef. de variação & $55,4 \%$ & $28217,3 \%$ & $27739,4 \%$ & $23092,3 \%$ & $20338,4 \%$ \\
Menor & $8.297,00$ & $293.011,93$ & $479.125,13$ & $205.537,33$ & $243.530,15$ \\
Maior & $220.813,00$ & $55.333 .700,95$ & $95.509 .074,14$ & $89.894 .754,29$ & $99.492 .903,45$ \\
$1^{\circ}$ quartil & $16.587,00$ & $18.345,00$ & $20.299,00$ & $22.725,00$ & $26.538,00$ \\
$3^{\circ}$ quartil & $28.270,00$ & $33.985,00$ & $46.073,00$ & $62.251,00$ & $77.890,00$ \\
\hline
\end{tabular}

Fonte: os autores (2019) 


\section{Gestãoe \\ Desenvolvimento}

e-ISSN: 2446-6875

p-ISSN: $1807-5436$

Para a variável PIB Per Capita, que é a soma de todos os bens e serviços finais de uma região dividido pelo número de habitantes, a Tabela 2 mostra que houve crescimento em cada período analisado dos municípios paranaenses, e ainda mais expressivo nos anos de 2015 e 2016, sendo que apresentaram elevação de 116\% e 157\% respectivamente, tomando com base o ano de 2012 que apresentou o menor valor. Esses dois períodos somados ainda apresentam 54\% de representatividade da variável média nos 5 anos, seguindo a mesma linha de crescimento do Pronaf que ocorre a cada período analisado. De acordo com a Tabela 2, nota-se um elevado valor de desvio padrão, exceto para o ano de 2012, com uma discrepância grande em relação aos valores médios.

\subsection{AGRUPAMENTO DOS MUNICÍPIOS}

A Figura 1, desenvolvida por meio do software Qgis, ilustra a distribuição geográfica dos agrupamentos dos municípios paranaenses separados por meio da análise de cluster.

Figura 1 - Distribuição espacial dos agrupamentos dos municípios paranaenses

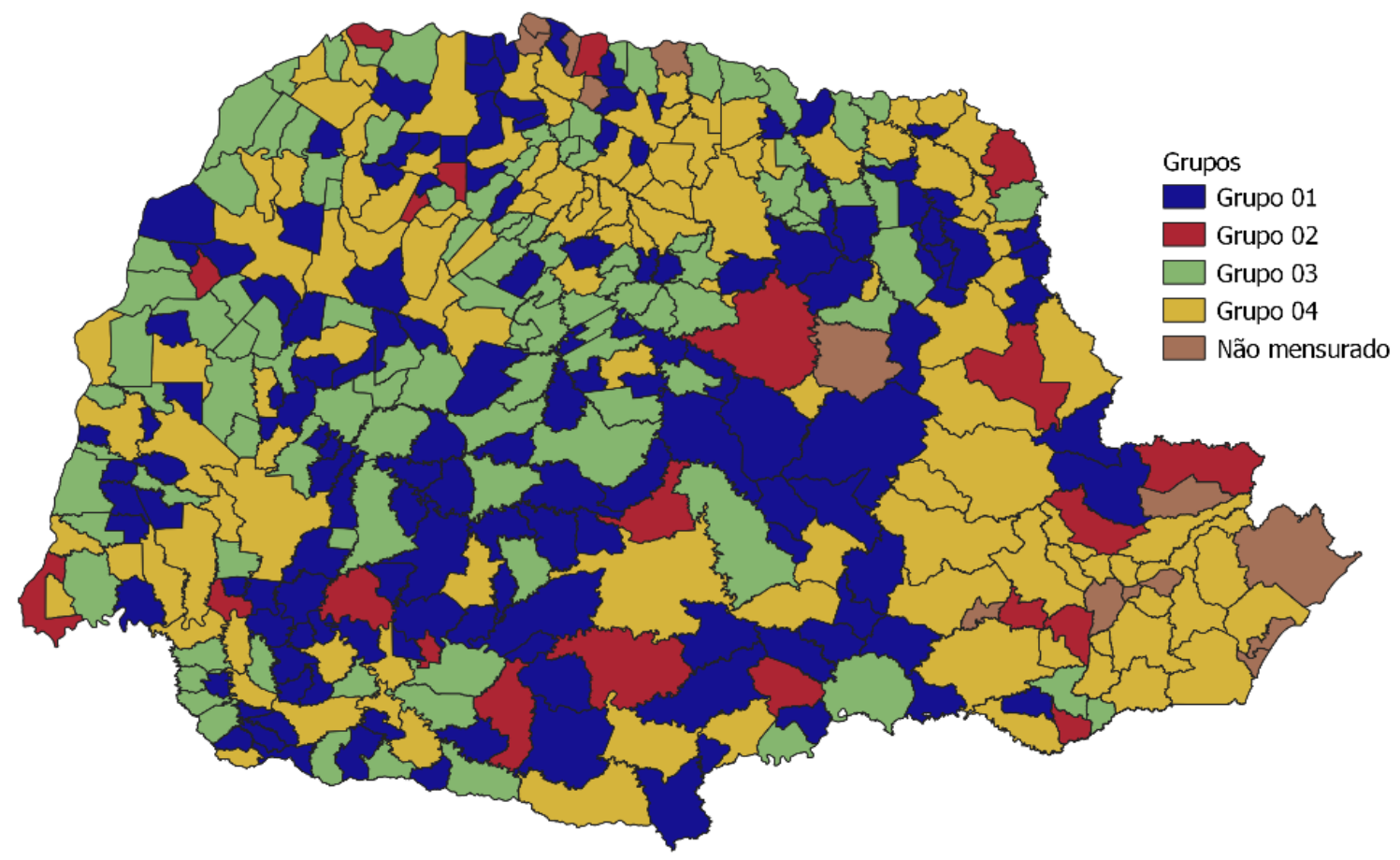

Fonte: os autores (2019)

Quanto ao número de grupos, uma vez que buscou identificar perfis que pudessem desenvolver análises e estratégias de ações, acredita-se que algo entre dois a seis agregados seja o adequado. Para 
uma seleção mais acurada, utilizou-se do coeficiente de aglomeração, o qual é indicado para uso em uma regra de parada e tem se apresentado como um algoritmo preciso, como indica Hair et al. (2009). Ao final, foram encontrados quatro agrupamentos: o grupo 01, que agrupou 142 municípios; o segundo grupo, com 21; o terceiro grupo, 107; e o quarto grupo, 115.

Na Tabela 3 contém as estatísticas descritivas dos dados agrupados (clusters) do Pronaf.

Tabela 3 - Médias e Desvio Padrão dos Dados do Pronaf Conforme os Agrupamentos

\begin{tabular}{clccccc}
\hline Grupo & Estatística & $\mathbf{2 0 1 2}$ & $\mathbf{2 0 1 3}$ & $\mathbf{2 0 1 4}$ & $\mathbf{2 0 1 5}$ & $\mathbf{2 0 1 6}$ \\
\hline \multirow{2}{*}{1} & Média & $4.905 .428,98$ & $6.387 .631,71$ & $7.564 .269,34$ & $7.364 .664,59$ & $7.964 .987,82$ \\
& Desvio Padrão & $4.415 .335,72$ & $6.048 .070,56$ & $6.967 .672,73$ & $7.024 .246,75$ & $7.628 .828,52$ \\
\multirow{2}{*}{2} & Média & $5.213 .516,14$ & $6.443 .180,04$ & $7.433 .512,58$ & $7.228 .668,30$ & $7.922 .433,77$ \\
& Desvio Padrão & $4.670 .727,87$ & $6.569 .127,25$ & $7.384 .168,08$ & $7.966 .837,90$ & $8.706 .447,80$ \\
\multirow{2}{*}{3} & Média & $7.524 .828,10$ & $9.025 .764,67$ & $11.114 .727,45$ & $11.289 .927,78$ & $12.634 .665,00$ \\
& Desvio Padrão & $7.453 .365,97$ & $9.105 .328,31$ & $11.361 .617,59$ & $11.637 .851,10$ & $13.941 .925,25$ \\
\multirow{2}{*}{4} & Média & $6.742 .134,66$ & $8.138 .156,79$ & $10.273 .830,14$ & $10.316 .597,87$ & $10.416 .816,55$ \\
& Desvio Padrão & $9.090 .127,12$ & $11.647 .243,13$ & $16.386 .149,51$ & $16.822 .030,25$ & $16.139 .915,20$ \\
\hline
\end{tabular}

Fonte: os autores (2019)

Esta tabela evidencia que os aportes apresentam crescimento uniforme para cada grupo com o decorrer dos anos analisados: no grupo 1, tomando como base o ano de 2012, que foi o primeiro ano de coleta, com o ano de 2016, que foi o último, houve um crescimento de 62,37\% e a faixa média de distribuição desse grupo no decorrer dos 5 anos foi de $R \$$ 6.800.000. Para o grupo 2, o crescimento foi de $51,96 \%$ e a média da distribuição para foi próximo de 7 milhões. No grupo 3, a evolução foi de 67,91\% e com aporte médio de $R \$ 10.300 .00$. Por fim, o grupo 4 obteve a maior evolução, sendo $77,55 \%$ de ascensão e valores médios na casa dos 9 milhões.

A seguir, na Tabela 4 tem-se os agrupamentos para o PIB Per Capita e suas estatísticas.

\begin{tabular}{clccccc}
\multicolumn{6}{c}{ Tabela 4 - Médias e Desvio Padrão dos Dados do Pronaf PIB Per Capita Conforme os Agrupamentos } \\
\hline Grupo & Estatística & $\mathbf{2 0 1 2}$ & $\mathbf{2 0 1 3}$ & $\mathbf{2 0 1 4}$ & $\mathbf{2 0 1 5}$ & $\mathbf{2 0 1 6}$ \\
\hline \multirow{2}{*}{1} & Média & $16.324,09$ & $19.709,39$ & $20.538,49$ & $22.112,44$ & $25.112,10$ \\
& Desvio Padrão & $4.988,26$ & $6.768,25$ & $7.003,34$ & $7.256,41$ & $8.795,04$ \\
2 & Média & $43.928,24$ & $46.939,76$ & $43.236,38$ & $50.758,05$ & $62.252,24$ \\
& Desvio Padrão & $42.682,80$ & $38.529,54$ & $20.121,35$ & $24.062,67$ & $33.571,19$ \\
3 & Média & $17.040,76$ & $20.970,06$ & $21.797,39$ & $23.909,64$ & $26.386,73$ \\
& Desvio Padrão & $5.556,95$ & $7.453,39$ & $7.747,22$ & $8.068,52$ & $9.226,32$ \\
4 & Média & $21.215,66$ & $24.533,55$ & $26.485,90$ & $28.270,01$ & $30.714,34$ \\
& Desvio Padrão & $9.640,65$ & $11.043,46$ & $11.146,31$ & $11.774,05$ & $12.308,39$ \\
\hline
\end{tabular}

Fonte: os autores (2019) 
Observamos na Tabela 4 que, exceto o grupo 2, que apresenta oscilações ao longo dos períodos, os demais 1, 3, e 4 apresentam evolução ao longo dos anos analisados. Tomando como base apenas o último ano de análise, em que os grupos apresentam seus maiores valores de PIB Per Capita, esse mesmo agrupamento 2 é o que apresenta o maior valor, sendo $R \$ 62.252,24$, seguido pelo grupo 3 com $\mathrm{R} \$ 30.714,34$, agrupamento 2 com $\mathrm{R} \$ 26.386,73$ e no 1 valor de $\mathrm{R} \$ 25.112,10$.

A Tabela 5 apresenta a composição do Valor Agregado Bruto dentro de três setores econômicos, sendo eles o do agronegócio, do comércio e da indústria. Essa proporção é demonstrada para cada agrupamento.

Tabela 5 - Composição do VAB nos setores da economia para os agrupamentos

\begin{tabular}{cccc}
\hline Rótulos de Linha & Agronegócio & Comércio & Indústria \\
\hline 1 & $58,80 \%$ & $32,20 \%$ & $9,00 \%$ \\
2 & $12,00 \%$ & $24,80 \%$ & $63,20 \%$ \\
3 & $40,30 \%$ & $49,90 \%$ & $9,90 \%$ \\
Total Geral & $17,90 \%$ & $55,50 \%$ & $26,60 \%$ \\
\hline
\end{tabular}

Fonte: os autores (2019)

No grupo 1 a composição que mais se destaca é do agronegócio, com 58,80\% do total. Além disso, este cluster é o que agrupou a maior parte dos municípios, um total de 142.Vale ressaltar que o grande grupo comércio é a segunda principal fonte de agregação de valores, $32,2 \%$, e a indústria influencia em apenas $9 \%$ do total.

0 agrupamento 2 tem 21 municípios e a economia depende mais deste setor, pois este segmento apresenta a maior participação, com 63,20\% do total. Ademais, este agrupamento apresentou, entre os 4 grupos, o maior percentual na indústria. O comércio e o agronegócio tiveram uma participação de $24,8 \%$ e $12,0 \%$, respectivamente.

O terceiro agrupamento, grupo 3, têm valores de composição próximos para o segmento do agronegócio e do comércio, 40,30\% e 49,90\% respectivamente, esse agrupamento conta com 107 municípios, que pela proporção giram suas economias com esses dois setores, contando com pouca participação do setor industrial. Da mesma forma que o grupo 1, este, pelo fato de ter o setor secundário - a indústria - pouco significativo, porém com o setor do comércio já bem representativo e com boa participação da agropecuária, pode levar a crer que a agropecuária pode influenciá-lo. 
No quarto agrupamento, que é composto por 115 municípios, o comércio é o principal setor econômico, com participação de 55,5\% do total. O segmento industrial e agropecuário aparece com uma participação de $26,6 \%$ e $17,9 \%$, respectivamente.

\subsection{ANÁLISE DO EFEITO DO PRONAF NO PIB PER CAPITA MUNICIPAL}

Nesta seção discute-se a avaliação do impacto do Pronaf no PIB per Capita Municipal durante o período. Para apreender estes efeitos, utilizou-se da análise de regressão linear com dados em painel. No geral, a análise de regressão consiste na realização de uma análise estatística com o objetivo de verificar a existência de uma relação funcional entre uma variável dependente com uma ou mais variáveis independentes. Em outras palavras consiste na obtenção de uma equação que tenta explicar a variação dependente pela variação dos níveis das variáveis independentes.

Os dados em painel têm uma capacidade de tratar o problema do viés de variável omitida, que é comum nas regressões cross-section. Com o emprego de modelos com dados em painel é possível controlar as variáveis omitidas fixas ao longo do tempo. A principal vantagem de utilizar os modelos de dados em painel se dá ao controle da heterogeneidade individual, ou seja, à possibilidade de se medirem separadamente os efeitos gerados por causa de diferenças existentes entre cada observação em cada cross-section, além de ser possível avaliar a evolução, para um dado indivíduo, das variáveis em estudo ao longo do tempo. (WOOLDRIDGE, 2010; FÁVERO, 2013).

Dois aspectos são importantes para caracterizar o modelo de análise de regressão com dados em painel. Primeiramente o modelo se caracteriza como um painel curto, em que o número de tempo é menor que o número de elemento ( $t<n)$. Em segundo, considerando que a variável dependente e os regressores podem apresentar oscilações simultaneamente ao longo dos períodos, bem como entre os indivíduos, esta pesquisa utilizou-se do within variance, que é conhecido pela variação ao longo do tempo ou para um dado indivíduo (FÁVERO, 2013).

A utilização de modelos que envolvam dados longitudinais tem sido recorrente, no entanto verificase uma falta de cuidado quanto aos critérios para a adoção de um modelo em detrimento de outro, bem como a ausência de uma discussão mais detalhada sobre os possiveis estimadores a serem estudados em cada situação (CASTRO; RESENDE; PIRES, 2014). Contudo, para que se chegue a resultados fidedignos, deve haver a definição do modelo mais consistente a ser adotado, em função das características dos dados. Assim, foi desenvolvido o teste LM de Breusch-Pagan, o teste F de Chow e o Teste de Hausman (WOOLDRIDGE, 2010; FÁVERO, 2013). 


\section{Gestãoe \\ Desenvolvimento}

e-ISSN: 2446-6875

p-ISSN: $1807-5436$

Tabela 6 - Teste LM de Breusch-Pagan, teste F de Chow e Teste de Hausman

\begin{tabular}{lccccc}
\hline Descrição & Paraná & Grupo 1 & Grupo 2 & Grupo 3 & Grupo 4 \\
\hline $\begin{array}{l}\text { Teste de Chow } \\
\text { Chi }^{2}\end{array}$ & 26,41 & 18,48 & 14,59 & 24,89 & 32,66 \\
p-valor & 0,0000 & 0,0000 & 0,0000 & 0,0000 & 0,0000 \\
\hline Teste de Breusch-Pagan & & & & \\
Chi & & & & \\
p-valor & 2656,19 & 813,65 & 109,81 & 668,98 & 850,89 \\
\hline Teste de Hausman & 0,0000 & 0,0000 & 0,0000 & 0,0000 & 0,0000 \\
Chi & & & & \\
p-valor & 14,39 & 21,07 & 0,01 & 35,64 & 2,34 \\
\hline \multicolumn{7}{c}{ Fonte: os autores (2019) } \\
\end{tabular}

O teste $\mathrm{F}$ de Chow utiliza-se para escolher entre os modelos Pooled e Efeitos Fixos. Se a estatística Chi for significativa o modelo de Efeitos Fixos é mais adequado. O teste LM de Breusch-Pagan é utilizado para escolher entre os modelos Pooled e de Efeitos Aleatórios, se a estatística Chi for significativa o modelo de Efeitos Aleatórios é mais adequado. Já o Teste de Hausman é utilizado para escolher entre os modelos de Efeitos Fixos e Efeitos Aleatórios, se a estatística Chi ${ }^{2}$ for significativa o modelo de Efeitos Aleatórios é mais adequado (WOOLDRIDGE, 2010; FÁVERO, 2013). Assim, para o estado do Paraná, grupos 1 e 3 o modelo de Efeitos Aleatórios foi o escolhido; para os grupos 2 e 4 o modelo de Efeito Fixo.

Tabela 7 - Resultados da regressão entre as variáveis

\begin{tabular}{cccccc}
\hline & Paraná & Grupo 1 & Grupo 2 & Grupo 3 & Grupo 4 \\
\hline Coeficiente & 0,0004164 & 0,0007022 & 0,0007056 & 0,0005083 & 0,0003093 \\
Estatística t & 13,23 & 14,30 & 0,85 & 13,68 & 8,13 \\
p-valor & 0,000 & 0,000 & 0,397 & 0,000 & 0,000 \\
\hline Constante & 20770,52 & 15957,76 & 44591,07 & 16775,92 & 23405,39 \\
Estatística t & 30,37 & 25,06 & 7,54 & 20,64 & 59,95 \\
p-valor & 0,000 & 0,000 & 0,000 & 0,000 & 0,000 \\
\hline Nro. de & & & & & \\
observações & 1,925 & 710 & 105 & 535 & 575 \\
Nro. de grupos & 385 & 142 & 21 & 107 & 115 \\
F ou Wald chi2 & 175,00 & 204,61 & 0,73 & 187,20 & 66,05 \\
p-valor & 0,0000 & 0,0000 & 0,3967 & 0,0000 & 0,0000 \\
R ajustado (within) & 0,1034 & 0,2699 & 0,0087 & 0,3396 & 0,1258 \\
\hline
\end{tabular}

Fonte: os autores (2019) 
De início pôde-se afirmar que há impactos positivos do Programa Nacional de Fortalecimento da Agricultura Familiar no crescimento econômico municipal, medido por meio do PIB per capta municipal, pois houve significância para os grupos 1, 3 e 4 (sendo o p-valor=0,0000, ou seja, $p<0,05$ ) e no estado do Paraná ( $p$-valor=0,000). Entretanto, regressão desenvolvida para o efeito do Pronaf no PIB per capta dos municípios não apresentou significância estatística no grupo 2 ( $p$-valor=0,3967, ou seja, p-valor>0,05). Adicionalmente, alguns outros dados podem ser explorados.

O coeficiente é interpretado como a relação de cada unidade da variável independente, o Pronaf, sobre a variável dependente, o PIB per capta municipal (BUENO; OLIVEIRA, 2015). Assim, de cada R\$1.000,00 financiados pelo Pronaf, o PIB per Capita Municipal é impactado em R\$ 0,7022; 0,5083; 0,3093 e 0,4164; respectivamente nos grupos 1, 3, e 4 e no estado do Paraná. Para melhor compreender, o coeficiente devese considerar que o PIB per capita é divisão do PIB municipal pelo número de habitantes no município, ou, seja, quanto caberia a cada indivíduo se todos recebessem partes iguais; e, mais importante, o volume de aporte realizado pelo Pronaf. Verifica-se um efeito médio de cerca de $\mathrm{R} \$ 5.593,00 ; \mathrm{R} \$ 6.422,00$ e $\mathrm{R} \$$ 3.221,00 no PIB per capta municipal dentro do período analisado para os grupos 1, 2 e 3, respectivamente.

Por sua vez, o intercepto corresponde ao valor da variável prevista que independe das variações em previsora, ou seja, o comportamento do PIB per capta municipal não explicado pelas variações no volume de recursos do Pronaf (BUENO; OLIVEIRA, 2015). Assim, para o estado do Paraná, nos grupos 1, 3 e 40 valor do PIB per capita municipal não explicado pelo Pronaf é R\$ 20.770,52; R\$ 15.957,76; R\$ 16.775,92 e $R \$ 23.405,39$.

Ainda, observa-se diferenças no efeito do Pronaf sob o PIB Per Capita ao longo do tempo (R ajudatado within). Este coeficiente de determinação $\left(r^{2}\right)$ mede o grau de ajustamento da reta estimada e pela verificação da significância dos coeficientes estimados, testando hipóteses sobre a nulidade ou não dos parâmetros dos modelos (BUENO; OLIVEIRA, 2015), ou seja, o tamanho do efeito foi maior para os municípios do grupo $3(0,3396)$ e grupo $1(0,2699)$ e menores para o $4(0,1258)$ e para o estado do Paraná $(0,1034)$.

Ademais, algumas questões podem explicar a não relação do Pronaf com o PIB per capita municipal no grupo 2. Em primeiro lugar, conforme Tabela 5, que menciona a participação dos setores da economia, para o grupo 2, discrepante dos demais grupos, o setor econômico da indústria apresenta 63,20\% de participação, já o comércio e o agronegócio, que só têm $24,8 \%$ e 12,00\% de representatividade, respectivamente, o que pode sinalizar uma dependência desses municípios em uma base urbana e industrial.

Outra questão que merece consideração é o montante de recursos destinados para o grupo 4. Na Tabela 3 verifica-se que este grupo entre os 4 é o segundo menor em recebimento de recursos, com 
média de 7 milhões de reais, característica atrelada à forte dependência da industrialização seguida do comércio, que pode ser fator determinante para não significância de resultados, tendo em vista que o grupo 1, que é o menor recebedor destes recursos, com 6,8 milhões de reais em média, em contrapartida tem, conforme a mesma tabela, forte dependência econômica nos setores do agronegócio, com 58,80\% da participação, e o setor industrial apenas 9\%.

Em suma, com a utilização da análise de agrupamentos foram realizadas, separadamente, avaliações de impacto do Pronaf em cada grupo de municípios e também para o estado do Paraná. Nos grupos 1, 3 e 4 foi possível verificar impactos positivos do Pronaf sobre as taxas de crescimento do PIB per capita municipal, já os resultados do grupo 2 caracterizaram-se pela ausência de impactos do Pronaf, enquanto para o estado do Paraná apreende-se o menor poder de explicação. Assim, como encontraram Mattei et al. (2007), Assunção e Chein (2007), Silva e Alves Filho (2009); Camara et al. (2010), Castro, Resende e Pieres (2014) , Bueno e Oliveira (2015), Marioni et al. (2016), pode-se apreender impactos positivos do Pronaf sobre o crescimento do PIB per capita municipal, inclusive estadual.

Adicionalmente, como constatado por Castro, Resende e Pires (2014), as diferenças encontradas entre os grupos dos municípios, também com o estado, demonstram a importância de se incluir uma análise regional mesmo em políticas de abrangência nacional.

Por fim, como afirma Santos (2001), nos pequenos e médios municípios brasileiros, a agricultura é um importante agente do desenvolvimento da economia, em que os incentivos no setor atuam como um efeito multiplicador de renda, fomentando os demais setores da economia. Em suma, o desenvolvimento e a distribuição de renda do setor rural condicionam e mantêm a qualidade de vida nos tipos de municípios mencionados.

\section{CONSIDERAÇÕES FINAIS E RESULTADOS}

O Pronaf nasceu em 1995 para o fortalecimento da agricultura familiar, tornando-se a maior política nacional de auxílio à agricultura familiar e ao desenvolvimento rural no país. Dentre os objetivos do programa, está a melhoria das condições sociais e financeira de seus beneficiários, o que ocorre por meio de crédito subsidiado, possibilitando ao agricultor a aquisição de recursos para a expansão e manutenção de sua produção agropecuária, acrescendo a sua renda rural e transformando, positivamente, o meio onde estão inseridos.

Esta pesquisa teve como objetivo principal avaliar os impactos nos municípios do estado do Paraná do Programa Nacional de Agricultura Familiar (Pronaf) entre o período de 2012 a 2016. Para tal, utilizou-se do instrumental econométrico de modelos de dados em painel. Por sua vez, foi realizada, separadamente, 
uma avaliação para grupos de municípios que foram agrupados pelo método de cluster, a fim de captar os impactos diferenciados do Pronaf para cada agrupamento.

No processo de modelagem da regressão, primeiramente foi realizado os Testes de LM de BreuschPagan, o teste $\mathrm{F}$ de Chow e o Teste de Hausman para identificar o tipo de modelo de dados em painel mais adequado para as análises, indicando que para o estado do Paraná e os grupos 1 e 3 o modelo de Efeitos Aleatórios é o mais adequado, enquanto para os grupos 2 e 4 o modelo de Efeito Fixo.

A análise através de agrupamentos possibilitou melhor detalhar os impactos positivos do Pronaf nos municípios do estado do Paraná, em que os grupos 1, 3 e 4 apontaram para uma relação positiva entre o Pronaf e o crescimento do PIB per capita municipal, com um tamanho de efeito de 0,1034; 0,2699; 0,3396 e 0,1258. Enquanto os grupos mencionados exibiram impactos positivos do Pronaf sobre o crescimento do PIB per capita, a avaliação do grupo 2 não mostrou impacto significativo.

O impacto nos municípios do estado do Paraná do Programa Nacional de Agricultura Familiar (Pronaf), constatado nesta pesquisa, corrobora os resultados de pesquisas similares (MATTEl et al., 2007; ASSUNÇÃO; CHEIN, 2007; SILVA; PIRES FILHO, 2009; CAMARA et al., 2010; CASTRO; RESENDE; PIRES, 2014; BUENO; OLIVEIRA, 2015; MARIONI et al., 2016; ARAÚJO; VIEIRA FILHO, 2018). Adicionalmente, os resultados demonstram a importância de se incluir uma análise de políticas públicas de abrangência nacional de modo regionalizado. Tal abordagem, como indicado por Castro, Resende e Pires (2014), permitiu evidenciar desempenhos diferenciados do Pronaf para grupos específicos de municípios, além de indicar que aperfeiçoamentos e modificações no programa podem ser conduzidos de forma apropriada para as especificidades dos grupos.

No geral, deve-se reconhecer que mais do que uma unidade produtiva rural, a agricultura familiar consegue manter atrelada ao seu vínculo afetivo com a terra e a família uma produção agropecuária adaptável ao meio onde se encontra, sendo assim responsável por geração de postos de trabalho e renda. Todavia, o agricultor familiar brasileiro permaneceu por muito tempo sem inserções tecnológicas. Assim, programas governamentais, como é o caso do Pronaf, são ferramentas para auxiliar esses produtores rurais a aumentarem sua renda e promover o desenvolvimento rural, potencializando suas competências (WESZ; TRENTIN, 2006).

Mas em limitação, a análise em diferentes escalas de grupos permitiu trazer resultados segmentados dos impactos do Pronaf sobre o PIB per capita municipal, devendo-se reconhecer que talvez o PIB per capita não seja o melhor indicador de desenvolvimento econômico, mas este estudo limitou-se, por hora, a verificar os impactos do Pronaf sobre esta variável apenas. 


\section{REFERÊNCIAS}

ARAUJO, J. de A.; VIEIRA FILHO, J. E. R. Análise dos Impactos do Pronaf na Agricultura do Brasil no Período de $\mathbf{2 0 0 7}$ a 2016. Texto para discussão. Brasília/Rio de Janeiro: Instituto de Pesquisa Econômica Aplicada, 2018.

ASSUNÇÃO, J.; CHEIN, F. Condições de crédito no Brasil Rural. Revista de Economia e Sociologia Rural, Piracicaba - SP, 45(02), 367-407, 2007.

BAIARDIL, A., ALENCAR, C. M. M. Agricultura familiar, seu interesse acadêmico, sua lógica constitutiva e sua resiliência no Brasil. Revista de Economia e Sociologia Rural, Piracicaba - SP, 52(1), p. 45-62, 2014.

BANCO CENTRAL DO BRASIL (BCB). Matriz de Dados do Crédito Rural - MDCR. Disponível em: https:// dadosabertos.bcb.gov.br/dataset/matrizdadoscreditorural Acesso em: maio 2019.

BANCO CENTRAL DO BRASIL (BCB). Resolução n. 2191, de 22 de agosto de 1995. Crédito Rural: Institui o Programa Nacional de Fortalecimento da Agricultura Familiar (PRONAF). Brasília, DF, 1995. Disponível em: http://www.bcb.gov.br/pre/normativos/res/1995/pdf/res_2191_v3_L.pdf. Acesso em: 28 abr. 2019.

BIANCHINI, V. Vinte anos do PRONAF, 1995-2015: avanços e desafios. 1. ed. Brasília: SAF/MDA, 2015.

BRESSER-PEREIRA, L. C. Desenvolvimento econômico e o empresário. Revista de administração de empresas, São Paulo, 2(4), 79-91, jan./abr., 1962.

BUAINAIN, A. M.; ROMEIRO, A. R.; GUANZIROLI, C. Agricultura familiar e o novo mundo rural. Sociologias, Porto Alegre, 5(10), 312-347, jul./dez., 2003.

BUENO, L. R.; OLIVEIRA, R. A. Impacto socioeconômico do Programa Nacional de Fortalecimento da Agricultura Familiar - Pronaf no estado do Paraná (2000-2006). Informe Gepec, Toledo, 19(1), 20-37, jan./ jun., 2015.

CAMARA, M. R. G. da et al. Pronaf: uma análise dos impactos sobre as economias locais do estado do Paraná. In: CONGRESSO DA SOCIEDADE BRASILEIRA DE ECONOMIA E SOCIOLOGIA RURAL - SOBER، 48. Anais... Campo Grande, MS, 2010.

CASTRO, C. N. de; RESENDE, G. M.; PIRES, M. J. de S. Avaliação dos Impactos Regionais do Programa Nacional da Agricultura Familiar (Pronaf). Texto para discussão. Brasília/Rio de Janeiro: Instituto de Pesquisa Econômica Aplicada, 2014. 
DAMASCENO, N. P.; KHAN, A. S.; LIMA, P. V. P. S. O impacto do Pronaf sobre a sustentabilidade da agricultura familiar, geração de emprego e renda no Estado do Ceará. Revista de economia e sociologia rural, Piracicaba, SP, 49(1), 129-156, jan./mar., 2011.

DE FARIA, R. B.; SANTOS, D. F. L. O crédito rural no brasil: o perfil das pesquisas acadêmicas. Revista Gestão e Desenvolvimento, Novo Hamburgo, v. 11, n. 2, 2014. DOI: 10.25112/rgd.v11i2.111.

FÁVERO, L. P. L. Dados em painel em contabilidade e finanças: teoria e aplicação. Brazilian Business Review, 10(1), 131-156., 2013.

FEIJÓ, R. The impact of a family farming credit programme on the rural economy of Brazil. In: CONGRESSO DE ECONOMIA, 29. 2001. Anais... Salvador, BA, 2001.

FIELD, A. Descobrindo a estatística usando o SPSS. Porto Alegre: Artmed, 2009.

FREITAS, A. F.; FREITAS, A. F.; DIAS, M. M. Mudanças conceituais do desenvolvimento rural e suas influências nas políticas públicas. Revista administração pública, 46 (6), 1575-1597, 2012.

GEHLEN, I. Políticas públicas e desenvolvimento social rural. São Paulo em perspectiva, São Paulo, 18 (2), 95-103, 2004.

HAIR, J. F.; BLACK, W. C.; BABIN, B. J.; ANDERSON, R. E.; TATHAM, R. L. Análise multivariada de dados. 6. ed. Porto Alegre: Bookman. 2009.

GUANZIROLI, C. E. Pronaf dez anos depois: resultados e perspectivas para o desenvolvimento rural. Revista de economia e sociologia rural, Rio de Janeiro, 45 (2), abr./jun., 2007.

HANAUER, L. dos S.; TEIXEIRA, O. A importância do crédito rural (Pronaf) no desenvolvimento da agricultura familiar no território rural da produção/RS. In: SEMINÁRIO DE JOVENS PESQUISADORES EM ECONOMIA E DESENVOLVIMENTO, II. Anais... Santa Maria, RS, 2015.

HOFFMANN, R. Distribuição de renda e crescimento econômico. Estudos avançados, São Paulo, 15 (4), p. 67-76, jan./abr., 2001.

INSTITUTO BRASILEIRO DE GEOGRAFIA E ESTÁTICAS (IBGE). Panorama econômico do Brasil. Brasília, 2019. Disponível em: https://ww2.ibge.gov.br/home/mapa_site/mapa_site.php\#economia. Acesso em: 09 jun. 2019. 
INSTITUTO BRASILEIRO DE GEOGRAFIA E ESTÁTICAS (IBGE). Bases Cartográficas. Brasília, 2018. Disponivel em: https://mapas.bge.gov.br/bases-e-referenciais/bases-cartograficas.html. Acesso em: 12 agosto de 2019.

INSTITUTO DE PESQUISAS ECONÔMICAS APLICADAS (IPEA). Carta de conjuntura. Brasília, 2018. Disponivel em: http://www.ipea.gov.br/portal/images/stories/PDFs/conjuntura/190417_cc_43_economia_mundial.pdf. Acesso em: 09 jun. 2019.

INSTITUTO PARANAENSE DE DESENVOLVIMENTO ECONOMICO E SOCIAL (IPARDES). Base de Dados do Estado - BDEweb. Disponivel em: http://www.ipardes.gov.br/imp/index.php. Acesso em: maio de 2019.

LOPES, P. F. et al. O Pronaf e as racionalidades da agricultura familiar. Estudos Sociedade e Agricultura, Rio de Janeiro, 24(1), 70-84, abr./set., 2016.

MARIONI, L. da S. et al. Uma Aplicação de Regressão Quantílica para Dados em Painel do PIB e do Pronaf. RESR, Piracicaba-SP, 54(2), 221-242, abr/jun., 2016.

MATTEI, L. et al. Uma análise dos impactos do Pronaf sobre as economias locais nas regiões Nordeste, Sudeste e Norte do Brasil. In: CONGRESSO DA SOCIEDADE BRASILEIRA DE ECONOMIA E SOCIOLOGIA RURAL - SOBER, 45. Anais... Londrina, PR, 2007.

MINISTÉRIO DO DESENVOLVIMENTO AGRÁRIO (MDA). Pronaf: 20 anos de apoio aos agricultores familiares. 2015. Disponivel em: http://www.mda.gov.br/sitemda/noticias/pronaf-20-anos-de-apoio-aos-agricultores-familiares. Acesso em: 20 mar. 2019.

MINISTÉRIO DO DESENVOLVIMENTO AGRÁRIO (MDA). Evolução histórica do Pronaf. 2017. Disponível em: http://www.mda.gov.br/sitemda/secretaria/saf-creditorural/evolu\%C3\%A7\%C3\%A3o-do-pronaf. Acesso em: 20 mar. 2019.

MINISTÉRIO dO DESENVOLVIMENTO AGRÁRIO (MDA). Agropecuária Brasileira em Números. 2019. Disponivel em: http://www.agricultura.gov.br/assuntos/politica-agricola/agropecuaria-brasileira-em-numeros. Acesso em: 09 jun. 2019.

NAVARRO, Z. Desenvolvimento rural no Brasil: os limites do passado e os caminhos para o futuro. Estudos Avançados, 15 (43), 83-100, set./dez., 2011.

OLIVEIRA, G. B. Uma discussão sobre o conceito de desenvolvimento. Revista da FAE, 5(2), 37-48, maio/ ago., 2002. 
ROSTOW, W. W. Etapas do desenvolvimento econômico: um manifesto não comunista. 6. ed. Rio de Janeiro: Zahar Editores. 1978.

SANTOS, M. J. Projeto alternativo de desenvolvimento rural sustentável. Estudos Avançados, São Paulo, 15(43), 225-238, set./dez., 2001.

SANTOS, E.; BITARELLO, J.; MONTARDO, S.; PEDDE, V. Capital Social, Políticas Públicas e Desenvolvimento Regional. Revista Gestão e Desenvolvimento, Novo Hamburgo, v. 9, n. 2, 2012. DOI: 10.25112/rgd. v9i2.1020.

SCHNEIDER, S. Situando o desenvolvimento rural no Brasil: o contexto e as questões em debate. Revista de Economia Política, São Paulo, 30 (3), 511-531, 2010.

SILVA, S. P.; PIRES FILHO, E. Impactos Econômicos do Pronaf em Territórios Rurais: Um Estudo para o Médio Jequitinhonha . REN - Revista Econômico do Nordeste, 40 (03), jul/set., 2009.

SOUZA, N. J. Desenvolvimento Econômico. 5. ed. São Paulo: Atlas. 2007.

WESZ JR., V. J. ; TRENTIN, I. C. L. Agregação de valor e desenvolvimento sustentável nos municípios rurais. Revista Gestão e Desenvolvimento, Novo Hamburgo, v. 3, n. 2, 2006. DOI: 10.25112/rgd.v3i2.845.

WOOLDRIDGE, J. M. Introdução à econometria: uma abordagem moderna. 2. ed. São Paulo: Cengage Learning. 2010. 